\title{
SDU\%
}

\section{Predictability concentrates in bad times. And so does disagreement}

by

\author{
Thiago de Oliveira Souza
}

Discussion Papers on Business and Economics

No. $8 / 2019$

FURTHER INFORMATION

Department of Business and Economics

Faculty of Business and Social Sciences University of Southern Denmark Campusvej 55, DK-5230 Odense M 


\title{
Predictability concentrates in bad times. And so does disagreement
}

\author{
Thiago de Oliveira Souza \\ University of Southern Denmark; \\ Danish Finance Institute
}

June 25, 2019

First draft: April 16, 2019. 


\begin{abstract}
Within a standard risk-based asset pricing framework with rational expectations, realized returns have two components: Predictable risk premiums and unpredictable shocks. In bad times, the price of risk increases. Hence, the predictable fraction of returns - and predictability - increases. "Disagreement" (dispersion in analyst forecasts) also intensifies in bad times if (i) analysts report (close to) risk-neutral expectations weighted by state prices, which become more volatile, or (ii) dividend volatility changes with the price of risk - for example, because consumption volatility changes. In both cases, individual analysts produce unbiased forecasts based on partial information.
\end{abstract}

JEL Code: G11, G12, G14.

Keywords: Predictability, bad times, efficient market hypothesis, disagreement, rational expectations. 


\section{Introduction}

There is evidence that past returns (Cujean and Hasler, 2017), news (Garcia, 2013), macro variables (Rapach et al., 2010; Henkel et al., 2011; Dangl and Halling, 2012), and analyst disagreement (Cen et al., 2016; Loh and Stulz, 2018), for example, are better return forecasters in bad times than in good times. The question is then, as posed by Cujean and Hasler (2017): "Why does return predictability [and analyst disagreement] concentrate in bad times?"

One possible answer, offered by Cujean and Hasler (2017) is, in summary, that a group of investors repeatedly uses the same wrong "model of fundamentals". This group coexists with another, which always uses the correct model. The mistakes of the first group are large enough to create market equilibrium "mispricing". However, the arbitrage opportunities between the two groups are never exploited; they generate return predictability instead. The mistakes of the first group are such that the two groups disagree, especially in bad times. Therefore, the explanation is consistent with both disagreement and predictability increasing in bad times. ${ }^{1}$ The theory is also consistent with time series momentum (Moskowitz et al., 2012) because predictability based on past returns, in particular, also increases in bad times.

The present paper offers an alternative theoretical answer to the same question posed by Cujean and Hasler (2017). Like Cujean and Hasler (2017), I demonstrate that stock return predictability and disagreement theoretically increase in bad times. This includes predictability based on past returns - time-series momentum - as a special case. Unlike Cujean and Hasler (2017), I do so within a general risk-based asset pricing framework with rational expectations, in the sense of Muth (1961) and Lucas (1972), and no arbitrage (nor violations of the law of one price). In particular, fully rational agents use the same correct

\footnotetext{
${ }^{1}$ Similar theories rely on other unobservable variables, apart from the models of fundamentals used by the investors. For example, the information content of economic signals (Veldkamp, 2005; Van Nieuwerburgh and Veldkamp, 2010), the fraction of noise traders (Chalkley and Lee, 1998), and the incorporation of news into stock prices (McQueen and Roley, 1993; Boyd et al., 2005) could all vary with the business cycle.
} 
"model of fundamentals" at every point in time (potentially based on different information sets).

I start by showing, in Section 2, that predictability increases in bad times. I impose almost no restrictions on the economy apart from no arbitrage, so that a unique stochastic discount factor (SDF) on the space of traded assets exists. The price of risk varies over time; "bad times" correspond to a high price of risk. In addition, the price of risk does not become relatively less volatile when it rises; the coefficient of variation does not decrease in bad times. Within this framework, only proxies for risk (and) or price of risk forecast returns. Past returns - responsible for time series momentum - must be one of these proxies, as in de Oliveira Souza (2019a), for example. The proxies are linear on their respective unobservable parameters, with possibly random coefficients. ${ }^{2}$ This allows for unexpected structural breaks (Lettau and Van Nieuwerburgh, 2008).

With no further assumptions, predictability increases in bad times, as I formally demonstrate. Return predictability, given by the $R^{2}$ of the predictive regressions, increases for models based on either risk or price of risk proxies in these states. There is a common economic explanation for the results involving both proxies: Risk premiums increase with the price of risk; they become a larger fraction of total returns relative to noise. Both risk and price of risk proxies forecast risk premiums. Noise, by definition, is unforecastable. Hence, the forecastable portion of returns increases with the price of risk. For price of risk proxies, in particular, a second similar effect reinforces the one just described: The fraction of the proxy determined by the unobservable price of risk also increases relative to the one determined by noise ("measurement error") when the price of risk increases. Changes in the proxy become more informative about changes in the price of risk when the variation in the price of risk is larger.

Section 2.3 shows that no further assumptions are needed to explain why "disagreement" about future dividends (payoffs in general) increases in bad times if analysts report quasi risk

\footnotetext{
${ }^{2}$ I do not model systematic changes in the link between individual proxies and the parameter that they capture because, in general, the link can strengthen with the price of risk, as in de Oliveira Souza (2019e), or not, as in de Oliveira Souza (2019a). Hence, this type of detailed analysis can only be made for individual proxies, and not for answering why predictability varies in general.
} 
neutral expectations in surveys. Individual analysts condition their rational expectations on incomplete information sets to determine the future state of the economy. In this case, the law of total variance implies that the dispersion in conditional expectations increases with the volatility of the discounted dividend process. A larger market price of risk corresponds to larger state price volatility and to a more volatile discounted dividend process as a consequence. This explains why the dispersion in surveys of (quasi) risk neutral expectations increases in bad times when the volatility of the underlying dividend process remains constant. It is purely a "discount rate" (Cochrane, 2011) effect.

Section 3 shows how the dispersion of forecasts can increase in bad times even if analysts report real expectations in surveys. Under this assumption, the dispersion in conditional (rational) expectations of dividends can only increase in bad times if the underlying dividend process becomes more volatile in bad times. The section shows that this happens - within a standard consumption-based asset pricing framework - as long as the risk aversion of the representative agent does not increase in recessions. In this case, the price of risk can only increase if consumption becomes more volatile. ${ }^{3}$ Larger consumption volatility corresponds to larger dividend volatility since both are related to the state of the economy. Hence, analyst disagreement increases in bad times, when dividend and consumption volatilities (and the price of risk) are high.

\footnotetext{
${ }^{3}$ This is in line with the empirical evidence for consumption expenditure in Boguth and Kuehn (2013), Tédongap (2015), and Bansal et al. (2016), for example. In addition, De Oliveira Souza (2019d) shows in a standard time-separable power utility framework that short run voluntary consumption is also highly heteroskedastic.
} 


\subsection{Related literature and contribution}

In terms of purpose, Cujean and Hasler (2017) is the closest related paper in the literature. Both papers provide theoretical answers to the same research questions, based on different assumptions. The main distinction is the assumption of rational expectations and no arbitrage in the present paper, which is inconsistent with the assumptions in Cujean and Hasler (2017).

By extension, the present paper also relates to the heterogeneous beliefs literature cited by Cujean and Hasler (2017) and to the literature on (analyst) disagreement more generally, as in Ottaviani and Sorensen (2015), Sadka and Scherbina (2007), Anderson et al. (2005), or Banerjee and Kremer (2010), for example. Its main contribution with respect to this literature is to explain how disagreement arises within a rational expectations framework.

The paper also relates to a large literature on time-varying predictability and timevarying coefficients in return forecasting regressions in general. Examples of this literature are Pyun (2019), Cassella and Gulen (2018), Henkel et al. (2011), Dangl and Halling (2012), Paye (2012), Pettenuzzo et al. (2014), and Johannes et al. (2014). The contribution in this case is to provide an explanation for these empirical results that does not require the assumption of agent irrationality.

Finally, the paper relates to traditional risk-based asset pricing models that allow for time variation in the price of risk. Cochrane $(2011,2017)$ discusses several of these models. The contribution to this literature is to explain that variations in the price of risk (for any reason) imply variations in return predictability. The paper also relates to the discussion about whether analysts answer surveys with risk neutral probabilities (Cochrane, 2017), or not (Adam et al., 2018). 


\section{A general risk-based asset pricing framework}

Let $\zeta=\left(\zeta_{t}\right)$ be the unique stochastic discount factor (SDF) that follows the continuous-time stochastic process

$$
d \zeta_{t}=-\zeta_{t}\left[r_{f, t} d t+\lambda_{t} d z_{t}\right]
$$

where $d z_{t}$ is a one-dimensional standard Brownian motion without loss of generality (Roll, 1977), and the stochastic processes, $r_{t}^{f}$ and $\lambda_{t}$, are the risk free rate and the market price of risk, respectively. This formulation imposes almost no restrictions on the asset pricing model, apart from no arbitrage (including the law of one price).

Let the price of asset $i, P_{i}=\left(P_{i, t}\right)$, follow the process

$$
d P_{i, t}=P_{i, t}\left[\mu_{i} d t+\sigma_{i, t} d z_{t}+\tilde{\sigma}_{i, t} d \tilde{z}_{t}\right]
$$

where $\sigma_{i, t}$ is a stochastic process representing the effective risk of the asset, $d \tilde{z}_{t}$ is another one-dimensional standard Brownian motion independent of $d z_{t}$, and $\tilde{\sigma}_{i, t}$ is a stochastic process representing unpriced volatility.

It is possible to show that the equilibrium expected excess rate of return on this asset (without intermediate dividends) is

$$
\mu_{i, t}-r_{f, t}=\sigma_{i, t} \lambda_{t}
$$

which highlights that the premium depends on the risk of the asset, $\sigma_{i, t}$, and also on the overall market price of risk, $\lambda_{t}$.

Let the mean of the price of risk process change over time, but with constant relative variation. The variable is log normally distributed with time-varying mean, $m_{t}$, and constant variance, $s^{2}$,

$$
\ln \lambda_{t} \sim \mathscr{N}\left(m_{t}, s^{2}\right)
$$


In this case, both the time $t$ conditional expectation of the price of risk,

$$
\mathrm{E}_{t}[\lambda]=\exp \left\{m_{t}+\frac{1}{2} s^{2}\right\}
$$

and its conditional variance,

$$
\operatorname{Var}_{t}(\lambda)=\mathrm{E}_{t}[\lambda]^{2}\left(\exp \left\{s^{2}\right\}-1\right)
$$

increase with the conditional mean parameter, $m_{t}$, while the coefficient of variation remains constant over time,

$$
C V_{\lambda} \equiv \frac{\sqrt{\operatorname{Var}_{t}(\lambda)}}{E_{t}[\lambda]}=\sqrt{\exp \left\{s^{2}\right\}-1}
$$

\subsection{The return forecasters}

Eq. (3) implies that realized excess returns, in discrete time, are given by

$$
R_{i, t+1}-r_{f, t}=\sigma_{i, t} \lambda_{t}+e_{i, t+1}
$$

where $e_{i, t+1}$ is an error term. For example, these shocks arise from changes in expected cash flows or unexpected changes in the price of risk from one period to the next (assuming that the risk of the asset, $\sigma_{i, t}$, remains constant). According to Eq. (3), only two variables forecast returns: The price of risk, $\lambda_{t}$, and the risk of the asset, $\sigma_{i, t}$. I investigate predictability based on both variables.

First, consider (linear) proxies for the price of risk, given by

$$
\Lambda_{t}=a_{\lambda, t}+b_{\lambda, t} \lambda_{t}+e_{\lambda, t}
$$

where the coefficients $a_{\lambda, t}$ and $b_{\lambda, t}$ are possibly time-varying, and $e_{\lambda, t}$ is an error term. The variables in this category are the ones typically used to predict the equity premium. Examples include the aggregate dividend-price ratio (Campbell and Shiller, 1988a,b), the 
default and term spreads (Fama and French, 1989), the investment-capital ratio (Cochrane, 1991), and the consumption-wealth ratio (Lettau and Ludvigson, 2001). ${ }^{4}$ Although they tend to be used to predict the equity premium, Eq. (8) shows that price of risk proxies also forecast the returns on (all) individual stocks (de Oliveira Souza, 2019c,b).

Next, consider risk proxies given by

$$
\Sigma_{i, t}=a_{\sigma, t}+b_{\sigma, t} \sigma_{t}+e_{\sigma, t}
$$

where the coefficients $a_{\sigma, t}$ and $b_{\sigma, t}$ can also vary over time and $e_{\sigma, t}$ is an error term. Risk proxies are the ones typically related to the cross-section of asset returns. For stock returns in particular, examples include the stocks' estimated market betas (Sharpe, 1964; Lintner, 1965); the firm's size, value, investment, or profitability (Fama and French, 2015); and realized returns (Jegadeesh and Titman, 1993; de Oliveira Souza, 2019a).

Under the hypothesis that past returns are risk proxies (de Oliveira Souza, 2019a; Berk et al., 1999), time series momentum (Moskowitz et al., 2012) should also increase in bad times. This explains why time series momentum is stronger in bad times, for example (Cujean and Hasler, 2017).

Without further assumptions, as I show next, predictability increases in bad times. In addition, analyst disagreement also increases in bad times without further assumptions if analysts use (quasi) risk neutral expectations to answer surveys. Section 3 later explains how disagreement increases with the price of risk within a consumption-based asset pricing framework even if analysts report physical expectations in surveys.

\footnotetext{
${ }^{4}$ Welch and Goyal (2008) list several others.
} 


\subsection{Return predictability}

Consider a general predictive regression for the return on asset $i$ based on a given price of risk proxy,

$$
R_{i, t+1}=\alpha_{\lambda}+\beta_{\lambda} \Lambda_{t}+\varepsilon_{i \lambda, t+1}
$$

where the coefficients $\alpha_{\lambda}$ and $\beta_{\lambda}$ are constants to be determined, and $\varepsilon_{i \lambda, t+1}$ is an error term. The equivalent to Eq. (11), based on a risk proxy, is

$$
R_{i, t+1}=\alpha_{\sigma}+\beta_{\sigma} \Sigma_{t}+\varepsilon_{i \sigma, t+1}
$$

"Return predictability" is given by the $R^{2}$ (coefficient of determination) of the regressions. For Eq. (11) and Eq. (12), $R^{2}$ is equal to the square of the sample correlation in time series between the asset returns and the proxy in question. We obtain $R_{R, \Lambda}^{2}$ and $R_{R, \Sigma}^{2}$ in Eq. (13) and Eq. (14), respectively, for the predictive regressions based on the price of risk proxy in Eq. (11) or based on the risk proxy in Eq. (12) as

$$
\begin{aligned}
& R_{R, \Lambda}^{2}=\rho_{R, \Lambda}^{2}=\left(\frac{\operatorname{Cov}\left(R_{i}, \Lambda\right)}{\sqrt{\operatorname{Var}\left(R_{i}\right)} \sqrt{\operatorname{Var}(\Lambda)}}\right)^{2}, \\
& R_{R, \Sigma}^{2}=\rho_{R, \Sigma}^{2}=\left(\frac{\operatorname{Cov}\left(R_{i}, \Sigma\right)}{\sqrt{\operatorname{Var}\left(R_{i}\right)} \sqrt{\operatorname{Var}(\Sigma)}}\right)^{2} .
\end{aligned}
$$

As the sample size increases, the sample correlation converges to the population correlation. Hence, it is possible to analyze predictability based on the population values under the assumption of a large enough estimation sample. I do this by calculating the variances and covariances in Eq. (13) and Eq. (14) based on the (population) description of returns in Eq. (8), and the (population) description of the proxies in Eq. (9) and Eq. (10), respectively. 


\subsubsection{Return predictability with price of risk proxies}

First, assume that the coefficients in Eq. (9) are constant over time, $a_{\lambda, t}=a_{\lambda}$ and $b_{\lambda, t}=b_{\lambda}$. Assume also that the risk of the asset in Eq. (8) is constant in the sample period used to estimate the predictive regression in Eq. (11), $\sigma_{i, t}=\sigma_{i}$.

Under these assumptions, substituting Eq. (8) and Eq. (9) in Eq. (13) simplifies the regression's $R^{2}$ to

$$
R_{R, \Lambda}^{2}=\left(\frac{\sigma_{i} b_{\lambda} \operatorname{Var}(\lambda)}{\sqrt{\sigma_{i}^{2} \operatorname{Var}(\lambda)+\operatorname{Var}\left(e_{i}\right)} \sqrt{b_{\lambda}^{2} \operatorname{Var}(\lambda)+\operatorname{Var}\left(e_{\lambda}\right)}}\right)^{2} .
$$

Next, let us re-write it as

$$
R_{R, \Lambda}^{2}=\frac{\left(\sigma_{i} b_{\lambda}\right)^{2}}{\left(\sigma_{i}^{2}+\frac{\operatorname{Var}\left(e_{i}\right)}{\operatorname{Var}(\lambda)}\right)\left(b_{\lambda}^{2}+\frac{\operatorname{Var}\left(e_{\lambda}\right)}{\operatorname{Var}(\lambda)}\right)}
$$

which increases with the variance of the price of risk if the variance of the two error terms remains constant, for example. Given that a larger mean of the price of risk in Eq. (4), $m_{t}$, also implies larger variance in Eq. (6), the equation shows that predictability increases with the price of risk (in "bad times"), holding all else constant.

Intuitively, two effects explain why predictability increases with the price of risk. First, the relative fraction of returns that can be predicted, which is the first term in Eq. (8), increases. Hence, predicting changes in the price of risk becomes more important to explain returns. Second, the fraction of the price of risk proxy that measures the price of risk, given by the middle term in Eq. (9), also increases relative to the noise in the measurement: A larger part of the variation of the proxy over time is due to variation in the price of risk. Hence, the proxy becomes more informative about the price of risk when the price of risk increases. These two effects reinforce each other and predictability increases. 
A little more algebra leads to the same conclusion if the proxy coefficients in Eq. (9) and the risk of the asset in Eq. (8) vary independently over time. In this case, the regression's $R^{2}$ in Eq. (13) becomes

$$
R_{R, \Lambda}^{2}=\left(\frac{\mathrm{E}\left[\sigma_{i}\right] \mathrm{E}\left[b_{\lambda}\right] \operatorname{Var}(\lambda)}{\sqrt{\operatorname{Var}\left(R_{i}\right)} \sqrt{\operatorname{Var}(\Lambda)}}\right)^{2}=\frac{\left(\mathrm{E}\left[\sigma_{i}\right] \mathrm{E}\left[b_{\lambda}\right]\right)^{2}}{\frac{\operatorname{Var}\left(R_{i}\right)}{\operatorname{Var}(\lambda)} \frac{\operatorname{Var}(\Lambda)}{\operatorname{Var}(\lambda)}},
$$

where both terms in the denominator decrease with the price of risk. The first term is

$$
\begin{aligned}
\frac{\operatorname{Var}\left(R_{i}\right)}{\operatorname{Var}(\lambda)} & =\frac{\operatorname{Var}\left(\sigma_{i}\right) \operatorname{Var}(\lambda)+\mathrm{E}\left[\sigma_{i}\right]^{2} \operatorname{Var}(\lambda)+\mathrm{E}[\lambda]^{2} \operatorname{Var}\left(\sigma_{i}\right)+\operatorname{Var}\left(e_{i}\right)}{\operatorname{Var}(\lambda)} \\
& =\operatorname{Var}\left(\sigma_{i}\right)+\mathrm{E}\left[\sigma_{i}\right]^{2}+C V_{\lambda}^{-2} \operatorname{Var}\left(\sigma_{i}\right)+\frac{\operatorname{Var}\left(e_{i}\right)}{\operatorname{Var}(\lambda)},
\end{aligned}
$$

where the coefficient of variation, $C V_{\lambda}$, is given by Eq. (7). The second term is

$$
\begin{aligned}
\frac{\operatorname{Var}(\Lambda)}{\operatorname{Var}(\lambda)} & =\frac{\operatorname{Var}\left(b_{\lambda}\right) \operatorname{Var}(\lambda)+\mathrm{E}\left[b_{\lambda}\right]^{2} \operatorname{Var}(\lambda)+\mathrm{E}[\lambda]^{2} \operatorname{Var}\left(b_{\lambda}\right)+\operatorname{Var}\left(a_{\lambda}+e_{\lambda}\right)}{\operatorname{Var}(\lambda)} \\
& =\operatorname{Var}\left(b_{\lambda}\right)+\mathrm{E}\left[b_{\lambda}\right]^{2}+C V_{\lambda}^{-2} \operatorname{Var}\left(b_{\lambda}\right)+\frac{\operatorname{Var}\left(a_{\lambda}+e_{\lambda}\right)}{\operatorname{Var}(\lambda)} .
\end{aligned}
$$

The economic intuition is the same for constant and random coefficients.

\subsubsection{Return predictability with risk proxies}

Let us now consider regressions using risk proxies instead of price of risk proxies. Again, let us assume, first, that the coefficients in Eq. (10) are constant over time, $a_{\sigma, t}=a_{\sigma}$ and $b_{\sigma, t}=b_{\sigma}$. The price of risk in Eq. (8) is also constant in the sample used to estimate the predictive regression in Eq. (12), $\lambda_{t}=\lambda$. Under these assumptions, substituting Eq. (8) and Eq. (10) in Eq. (14) simplifies the regression's $R^{2}$ to

$$
R_{R, \Sigma}^{2}=\left(\frac{\lambda b_{\sigma} \operatorname{Var}\left(\sigma_{i}\right)}{\sqrt{\lambda^{2} \operatorname{Var}\left(\sigma_{i}\right)+\operatorname{Var}\left(e_{i}\right)} \sqrt{b_{\sigma}^{2} \operatorname{Var}\left(\sigma_{i}\right)+\operatorname{Var}\left(e_{\sigma}\right)}}\right)^{2} .
$$


The equation can also be re-written as

$$
R_{R, \Sigma}^{2}=\frac{\left(b_{\sigma} \operatorname{Var}\left(\sigma_{i}\right)\right)^{2}}{\left(\operatorname{Var}\left(\sigma_{i}\right)+\frac{\operatorname{Var}\left(e_{i}\right)}{\lambda^{2}}\right)\left(b_{\sigma}^{2} \operatorname{Var}\left(\sigma_{i}\right)+\operatorname{Var}\left(e_{\sigma}\right)\right)}
$$

which, all else being constant, increases with the price of risk, $\lambda$. This confirms that predictability based on risk proxies also increases with the price of risk (in "bad times").

The intuition of the result above is a little different from the one involving price of risk proxies. The main difference is that there is only one channel for the increase in predictability for risk proxies: The risk proxy does not become more informative about the risk of the asset because the fraction of the risk proxy that measures risk, the middle term in Eq. (10), is independent of the price of risk. This contrasts with the result involving the price of risk proxy. However, the relative fraction of returns that can be predicted, the first term in Eq. (8), still increases with the price of risk, as mentioned earlier. Hence, predicting changes in risk (not only changes in the price of risk) becomes more important to explain returns in this case. This explains why predictability based on risk proxies also increases in bad times.

A little more algebra shows, again, that these conclusions hold if the proxy coefficients in Eq. (10) and the price of risk in Eq. (8) vary independently over time. In this case, the regression's $R^{2}$ in Eq. (14) becomes

$$
R_{R, \Sigma}^{2}=\left(\frac{\mathrm{E}[\lambda] \mathrm{E}\left[b_{\sigma}\right] \operatorname{Var}\left(\sigma_{i}\right)}{\sqrt{\operatorname{Var}\left(R_{i}\right)} \sqrt{\operatorname{Var}(\Sigma)}}\right)^{2}=\frac{\left(\mathrm{E}\left[b_{\sigma}\right] \operatorname{Var}\left(\sigma_{i}\right)\right)^{2}}{\frac{\operatorname{Var}\left(R_{i}\right)}{\mathrm{E}[\lambda]^{2}} \operatorname{Var}(\Sigma)}
$$

where the first term in the denominator decreases with the price of risk, while the other remains constant. The first term is

$$
\begin{aligned}
\frac{\operatorname{Var}\left(R_{i}\right)}{\mathrm{E}[\lambda]^{2}} & =\frac{\operatorname{Var}\left(\sigma_{i}\right) \operatorname{Var}(\lambda)+\mathrm{E}\left[\sigma_{i}\right]^{2} \operatorname{Var}(\lambda)+\mathrm{E}[\lambda]^{2} \operatorname{Var}\left(\sigma_{i}\right)+\operatorname{Var}\left(e_{i}\right)}{\mathrm{E}[\lambda]^{2}} \\
& =C V_{\lambda}^{2}\left(\operatorname{Var}\left(\sigma_{i}\right)+\mathrm{E}\left[\sigma_{i}\right]^{2}\right)+\operatorname{Var}\left(\sigma_{i}\right)+\frac{\operatorname{Var}\left(e_{i}\right)}{\mathrm{E}[\lambda]^{2}}
\end{aligned}
$$


where the coefficient of variation, $C V_{\lambda}$, is given by Eq. (7).

\subsection{Disagreement in surveys of (quasi) risk neutral expectations}

Cochrane $(2011,2017)$ explains that analysts seem to report risk neutral expectations in surveys. This section shows that "disagreement", given by the dispersion in analyst answers to surveys about future payoffs (dividends), increases with the price of risk in this case. This conclusion holds whether analysts report risk neutral expectations in a strict sense or whether they use a different (and possibly time-varying) rate to discount their expectations. For example, Adam et al. (2018) argue that agents do not report exact risk neutral probabilities: The expected returns reported in surveys are systematically larger than the risk-free rate. However, the conclusions that I present hold regardless of the actual rate used to discount expectations. It is only important that the expectation contains a risk adjustment.

Assume that analysts answer surveys based on risk neutral expectations, $\mathrm{E}_{\mathbb{Q}}$. They do so based on signals, $\Omega$, about the future state of the economy. Without loss of generality, the risk-free rate is zero. ${ }^{5}$ Hence, a given analyst reports his expectation of a future dividend payment, $D_{t+1}$, conditioned on signal $\Omega=\omega$ as

$$
\mathrm{E}_{\mathbb{Q}}\left[D_{t+1} \mid \Omega=\omega\right]=\mathrm{E}\left[\zeta_{t+1} D_{t+1} \mid \Omega=\omega\right]=\zeta_{\omega, t+1} D_{\omega, t+1},
$$

where $\zeta_{\omega, t+1}$ and $D_{\omega, t+1}$ are, respectively, the SDF and the dividend payment in state $\omega$.

Individual analysts only have access to partial information. But they process this information perfectly: All forecasts are unbiased given the signal on which they are conditioned.

\footnotetext{
${ }^{5}$ We can change the probability measure to (possibly) generate a risk-neutral expectation, similar to Eq. (28), as

$$
P_{t}=\mathrm{E}\left[\zeta_{t+1} D_{t+1}\right]=\frac{\mathrm{E}_{\mathbb{Q}}\left[D_{t+1}\right]}{1+\tilde{r}_{t}},
$$

where $\mathrm{E}_{\mathbb{Q}}[]$ is (strictly) the risk neutral expectation if the expected value $\mathrm{E}_{\mathbb{Q}}\left[D_{t+1}\right]$ is discounted at the riskfree rate, $\tilde{r}_{t}=r_{f}$. A different discount rate, $\tilde{r}_{t}>r_{f}$ (Adam et al., 2018), simply multiplies the expectation by a different constant. It has no impact on the cross-sectional analysis that follows. Thus, I use $\tilde{r}_{t}=0$ for simplicity.
} 
In addition, the distribution of signals among the analysts reflects the true probabilities of each state. Hence, the analysts are also collectively correct in their expectations about the (discounted) dividend payment, which is always equal to the price of the asset,

$$
P_{t}=\mathrm{E}\left[\mathrm{E}\left[\zeta_{t+1} D_{t+1} \mid \Omega\right]\right]=\mathrm{E}\left[\zeta_{t+1} D_{t+1}\right] .
$$

For example, this implies that prices reflect all available information at every point in time or, equivalently, that there is no "mispricing".

We can now use the law of total variance to analyze the dispersion in analyst forecasts in Eq. (28). Without the $t+1$ subscripts to save on notation, we obtain

$$
\begin{aligned}
\operatorname{Var}\left(\mathrm{E}_{\mathbb{Q}}[D \mid \Omega]\right) & =\operatorname{Var}(\mathrm{E}[\zeta D \mid \Omega]) \\
& =\operatorname{Var}(\zeta D)-\mathrm{E}[\operatorname{Var}(\zeta D \mid \Omega)]
\end{aligned}
$$

where $\operatorname{Var}(\zeta D \mid \Omega)$ denotes the variance of the discounted dividend conditioned on signal $\Omega$. This conditional variance is zero for every (constant) forecast,

$$
\operatorname{Var}\left(\zeta_{\omega} D_{\omega} \mid \Omega=\omega\right)=0 \quad \forall \Omega,
$$

under the assumption that the signal $\Omega$ determines a given state of the economy, $\omega$, as shown in Eq. (28). Hence, Eq. (31) reduces to

$$
\operatorname{Var}\left(\mathrm{E}_{\mathbb{Q}}[D \mid \Omega]\right)=\operatorname{Var}(\zeta D),
$$

which establishes that analyst "disagreement", given by the variance of their conditional (risk neutral) expectations about dividends (on the left-hand side) is simply equal to the variance of discounted dividends (on the right-hand side). 


\subsubsection{Disagreement in surveys of risk neutral expectations in bad times}

The price of risk, $\lambda_{t}$ in Eq. (1), increases and the SDF, $\zeta_{t}$, becomes more volatile in bad times. In order to represent this change, let the SDF in bad times, $\zeta_{h}$, be a mean preserving spread of the SDF in good times, $\zeta_{l}$,

$$
\zeta_{h}=\zeta_{l}+z
$$

where $z$ is a random variable with zero mean, positive variance, and orthogonal to the SDF, $\zeta$, and to dividends, $D$,

$$
\mathrm{E}[z]=0, \quad \operatorname{Var}(z)>0, \quad z \perp \zeta, \quad z \perp D
$$

In this formulation, the SDF has constant mean but larger variance in bad times, so I focus on changes in risk premiums,

$$
\begin{aligned}
\operatorname{Var}\left(\zeta_{h}\right) & =\operatorname{Var}\left(\zeta_{l}\right)+\operatorname{Var}(z) \\
\mathrm{E}\left[\zeta_{h}\right] & =\mathrm{E}\left[\zeta_{l}\right]
\end{aligned}
$$

The dispersion in analyst forecasts in bad times, equivalent to Eq. (33), is given by

$$
\operatorname{Var}\left(\mathrm{E}_{\mathbb{Q}, h}[D \mid \Omega]\right)=\operatorname{Var}\left(\zeta_{h} D\right)=\operatorname{Var}\left(\zeta_{l} D\right)+\operatorname{Var}(z D)
$$


where the second equality comes from Eq. (34) and Eq. (35). ${ }^{6}$ Finally, substitute Eq. (33) in Eq. (38) for $\zeta_{l}$,

$$
\operatorname{Var}\left(\mathrm{E}_{\mathbb{Q}, h}[D \mid \Omega]\right)=\operatorname{Var}\left(\mathrm{E}_{\mathbb{Q}, l}[D \mid \Omega]\right)+\operatorname{Var}(z D)
$$

where $\mathrm{E}_{\mathbb{Q}, l}[D \mid \Omega]$ is the dispersion in conditional analyst expectations of dividends in good times. This equation shows that analyst forecasts are more dispersed when the price of risk increases.

\section{Consumption-based asset pricing and disagreement}

This section explains that analyst disagreement also increases in bad times within a general consumption-based asset pricing framework with heteroskedastic consumption. Boguth and Kuehn (2013), Tédongap (2015), and Bansal et al. (2016), for example, provide evidence of time-varying consumption expenditure volatility. De Oliveira Souza (2019d) shows that short run voluntary consumption is also highly heteroskedastic, based on a standard time-separable power utility framework. Disagreement increases with the price of risk in proportion to consumption volatility, even if analysts report expected values using real probabilities in this case.

\footnotetext{
${ }^{6}$ The covariance term is zero because the variable $z$ has mean zero and it is orthogonal to the other variables:

$$
\operatorname{Cov}\left(\zeta_{l} D, z D\right)=\mathrm{E}\left[\zeta_{l} D z D\right]-\mathrm{E}\left[\zeta_{l} D\right] \mathrm{E}[z D],
$$

where both terms on the right-hand side are zero according to Eq. (35):

$$
\begin{aligned}
& \mathrm{E}\left[\zeta_{l} D z D\right]=\operatorname{Cov}\left(\zeta_{l} D^{2}, z\right)+\mathrm{E}\left[\zeta_{l} D^{2}\right] \mathrm{E}[z]=0, \\
& \mathrm{E}\left[\zeta_{l} D\right] \mathrm{E}[z D]=\mathrm{E}\left[\zeta_{l} D\right](\operatorname{Cov}(z, D)+\mathrm{E}[z] \mathrm{E}[D])=0 .
\end{aligned}
$$




\subsection{A standard endowment economy}

The representative agent chooses consumption, $c=\left(c_{t}\right)$, to maximize his time-separable expected utility,

$$
\max _{c=\left(c_{t}\right)} \mathbb{E}\left[\int_{0}^{T} e^{-\delta t} u\left(c_{t}\right)\right],
$$

subject to the budget constraint

$$
\mathbb{E}\left[\int_{0}^{T} \zeta_{t} c_{t} d t\right] \leq \mathbb{E}\left[\int_{0}^{T} \zeta_{t} e_{t} d t\right],
$$

where the right-hand side is the present value of the endowment process, $e=\left(e_{t}\right)$, and the left-hand side is the present value of consumption, $c$. This optimization induces the SDF

$$
\zeta_{t}=e^{-\delta t} \frac{u^{\prime}\left(c_{t}\right)}{u^{\prime}\left(c_{0}\right)} .
$$

For a given diffusion process for equilibrium consumption,

$$
d c_{t}=c_{t}\left[\mu_{c, t} d t+\sigma_{c, t} d z_{t}\right],
$$

an application of Itô's lemma based on Eq. (45) gives the standard consumption-based SDF dynamics corresponding to Eq. (1) (without specifying the drift term),

$$
d \zeta_{t}=-\zeta_{t}\left[r_{f, t} d t+\gamma\left(c_{t}\right) \sigma_{c, t} d z_{t}\right],
$$

where the market price of risk is the risk aversion coefficient for the utility function, $\gamma\left(c_{t}\right)$, multiplied by consumption volatility, $\lambda_{t}=\gamma\left(c_{t}\right) \sigma_{c, t}$. Under this formulation, the price of risk can increase if either risk aversion or consumption volatility increases. In this section, I assume that risk aversion remains constant over time. Therefore, the price of risk only changes with consumption volatility. 


\subsection{Dividends and aggregate consumption}

Let the dividends of firm $i, D_{i}$, be a share of aggregate consumption, $h_{i}$, such that

$$
D_{i, t}=c_{t} h_{i, t},
$$

with $h_{i, t}$ following the diffusion

$$
d h_{i, t}=h_{i, t}\left[\mu_{h i, t} d t+\sigma_{h i, t} d z_{h, t}\right]
$$

where $\mu_{h i, t}$ and $\sigma_{h i, t}$ are stochastic processes, and $d z_{h, t}$ is a standard Brownian motion independent of $d z_{t}$. Given the consumption process in Eq. (46), these two equations imply that dividends, $D_{i}$, follow the diffusion

$$
d D_{i, t}=D_{i, t}\left[\left(\mu_{c, t}+\mu_{h i, t}\right) d t+\sigma_{c, t} d z_{t}+\sigma_{h i, t} d z_{h, t}\right]
$$

Intuitively, this equation shows that individual firms tend to generate more cash flows when the aggregate economy is doing well, and vice versa. In fact, it is this positive covariance with aggregate consumption that makes stocks risky. Firms in stable growth, for example, are the ones with zero drift in Eq. (49). The equation also shows that dividend volatility has two sources: Idiosyncratic firm volatility, given by shocks to the firm's market share, $\sigma_{h i, t}$, and systematic shocks, $\sigma_{c, t}$. This formulation is also consistent with, for example, the impact that aggregate shocks have on firm output (Bloom, 2009).

\subsection{Disagreement in surveys of real expectations}

Let analysts now answer surveys based on real probabilities. They continue to do so based on signals, $\Omega$, about the future state of the economy. Hence, the analyst reports his expectation of a future dividend payment, $D_{t+1}$, conditioned on signal $\Omega=\omega$ as

$$
\mathrm{E}\left[D_{t+1} \mid \Omega=\omega\right]=D_{\omega, t+1} .
$$


The distribution of signals among the analysts follows the true state probabilities,

$$
\mathrm{E}\left[\mathrm{E}\left[D_{t+1} \mid \Omega\right]\right]=\mathrm{E}\left[D_{t+1}\right]
$$

which implies that the analysts are collectively correct about expected dividends. The individual forecasts are fully rational and unbiased, conditioned on the analyst's (incomplete) information set, $\Omega$.

We can use the law of total variance again to analyze the dispersion in analyst forecasts (without the $t+1$ subscripts),

$$
\operatorname{Var}(\mathrm{E}[D \mid \Omega])=\operatorname{Var}(D)-\mathrm{E}[\operatorname{Var}(D \mid \Omega)]
$$

where $\operatorname{Var}(D \mid \Omega)$ is the variance of the dividend conditioned on the signal $\Omega$. This variance is zero for every forecast,

$$
\operatorname{Var}\left(D_{\omega} \mid \Omega=\omega\right)=0 \quad \forall \Omega
$$

under the assumption that $\Omega$ determines a given state of the economy, $\omega$, as shown in Eq. (51), so that the conditional dividend is a constant. Hence, Eq. (53) reduces to

$$
\operatorname{Var}(\mathrm{E}[D \mid \Omega])=\operatorname{Var}(D)
$$

which is similar to Eq. (33) and establishes that analyst disagreement, given by the variance in conditional dividend expectations (on the left-hand side) is proportional to the conditional volatility of the dividend process in Eq. (50) (on the right-hand side).

Disagreement increases in bad times: In bad times, the price of risk, $\lambda_{t}$, increases. Under the assumption that risk aversion, $\gamma\left(c_{t}\right)$, remains constant, this must correspond to an increase in consumption volatility, $\sigma_{c, t}$ according to Eq. (47). A larger consumption volatility also increases the volatility of the dividend process in Eq. (50). As a consequence, the dispersion in analyst forecasts increases according to Eq. (55). This explains why 
analyst disagreement increases in bad times even if they answer surveys based on real expectations.

\section{Conclusion}

In this paper we learn that predictability, including predictability based on past returns, increases in bad times within a very general risk-based asset pricing framework. We also learn that analyst responses to surveys about future payoffs become more dispersed in the same periods, under the hypothesis that their answers reflect risk neutral (rational) expectations based on partial information.

Under the alternative hypothesis that analysts report real (rational) expectations, we learn that disagreement also increases within a standard consumption-based asset pricing framework in which the representative agent has constant risk aversion over time.

In summary, we learn that none of these empirical patterns can be regarded as evidence against the rational expectations paradigm, the efficient market hypothesis, or risk-based asset pricing theories. 


\section{References}

Adam, Klaus, Dmitry Matveev, and Stefan Nagel, 2018, Do survey expectations of stock returns reflect risk-adjustments?, Unpublished NBER working paper.

Anderson, Evan W., Eric Ghysels, and Jennifer L. Juergens, 2005, Do Heterogeneous Beliefs Matter for Asset Pricing?, Review of Financial Studies 18, 875-924.

Banerjee, Snehal, and Ilan Kremer, 2010, Disagreement and learning: Dynamic patterns of trade, Journal of Finance 65, 1269-1302.

Bansal, Ravi, Dana Kiku, and Amir Yaron, 2016, Risks for the long run: Estimation with time aggregation, Journal of Monetary Economics 82, 52-69.

Berk, Jonathan B., Richard C. Green, and Vasant Naik, 1999, Optimal investment, growth options, and security returns, Journal of Finance 54, 1553-1607.

Bloom, Nicholas, 2009, The impact of uncertainty shocks, Econometrica 77, 623-685.

Boguth, Oliver, and Lars-Alexander Kuehn, 2013, Consumption volatility risk, Journal of Finance 68, 2589-2615.

Boyd, John H., Jian Hu, and Ravi Jagannathan, 2005, The stock market's reaction to unemployment news: Why bad news is usually good for stocks, Journal of Finance 60, 649-672.

Campbell, John Y., and Robert J. Shiller, 1988a, Stock prices, earnings, and expected dividends, Journal of Finance 43, 661-676.

Campbell, John Y., and Robert J. Shiller, 1988b, The dividend-price ratio and expectations of future dividends and discount factors, Review of Financial Studies 1, 195-228.

Cassella, Stefano, and Huseyin Gulen, 2018, Extrapolation Bias and the Predictability of Stock Returns by Price-Scaled Variables, Review of Financial Studies 31, 4345-4397. 
Cen, Ling, K. C. John Wei, and Liyan Yang, 2016, Disagreement, underreaction, and stock returns, Management Science 63, 1214-1231.

Chalkley, Martin, and In Ho Lee, 1998, Learning and asymmetric business cycles, Review of Economic Dynamics 1, 623-645.

Cochrane, John H., 1991, Production-based asset pricing and the link between stock returns and economic fluctuations, Journal of Finance 46, 209-237.

Cochrane, John H., 2011, Presidential Address: Discount rates, Journal of Finance 66, 1047-1108.

Cochrane, John H., 2017, Macro-finance, Review of Finance 21, 945-985.

Cujean, Julien, and Michael Hasler, 2017, Why does return predictability concentrate in bad times?, Journal of Finance 72, 2717-2758.

Dangl, Thomas, and Michael Halling, 2012, Predictive regressions with time-varying coefficients, Journal of Financial Economics 106, 157-181.

de Oliveira Souza, Thiago, 2019a, A critique of momentum anomalies, Unpublished working paper. University of Southern Denmark.

de Oliveira Souza, Thiago, 2019b, A cross-sectional theory of price of risk proxies, Unpublished working paper. University of Southern Denmark.

de Oliveira Souza, Thiago, 2019c, Macro-finance and factor timing: Time-varying factor risk and price of risk premiums, Unpublished working paper. University of Southern Denmark.

de Oliveira Souza, Thiago, 2019d, Red tape asset pricing, Unpublished working paper. University of Southern Denmark. 
de Oliveira Souza, Thiago, 2019e, Size-related risk premiums, Unpublished working paper. University of Southern Denmark.

Fama, Eugene F., and Kenneth R. French, 1989, Business conditions and expected returns on stocks and bonds, Journal of Financial Economics 25, 23-49.

Fama, Eugene F, and Kenneth R. French, 2015, A five-factor asset pricing model, Journal of Financial Economics 116, 1-22.

Garcia, Diego, 2013, Sentiment during recessions, Journal of Finance 68, 1267-1300.

Henkel, Sam J., J. Spencer Martin, and Federico Nardari, 2011, Time-varying short-horizon predictability, Journal of Financial Economics 99, 560-580.

Jegadeesh, Narasimhan, and Sheridan Titman, 1993, Returns to buying winners and selling losers: Implications for stock market efficiency, Journal of Finance 48, 65-91.

Johannes, Michael, Arthur Korteweg, and Nicholas Polson, 2014, Sequential learning, predictability, and optimal portfolio returns, Journal of Finance 69, 611-644.

Lettau, Martin, and Sydney Ludvigson, 2001, Consumption, aggregate wealth, and expected stock returns, Journal of Finance 56, 815-849.

Lettau, Martin, and Stijn Van Nieuwerburgh, 2008, Reconciling the return predictability evidence, Review of Financial Studies 21, 1607-1652.

Lintner, John, 1965, The valuation of risk assets and the selection of risky investments in stock portfolios and capital budgets, Review of Economics and Statistics 47, 13-37.

Loh, Roger K., and Rene M. Stulz, 2018, Is sell-side research more valuable in bad times?, Journal of Finance 73, 959-1013.

Lucas, Robert E., 1972, Expectations and the neutrality of money, Journal of Economic Theory 4, 103-124. 
McQueen, Grant, and V. Vance Roley, 1993, Stock prices, news, and business conditions, Review of Financial Studies 6, 683-707.

Moskowitz, Tobias J., Yao Hua Ooi, and Lasse Heje Pedersen, 2012, Time series momentum, Journal of Financial Economics 104, 228-250.

Muth, John F., 1961, Rational expectations and the theory of price movements, Econometrica $29,315-335$.

Ottaviani, Marco, and Peter Norman Sorensen, 2015, Price reaction to information with heterogeneous beliefs and wealth effects: Underreaction, momentum, and reversal, American Economic Review 105, 1-34.

Paye, Bradley S., 2012, Deja vol: Predictive regressions for aggregate stock market volatility using macroeconomic variables, Journal of Financial Economics 106, 527-546.

Pettenuzzo, Davide, Allan Timmermann, and Rossen Valkanov, 2014, Forecasting stock returns under economic constraints, Journal of Financial Economics 114, 517-553.

Pyun, Sungjune, 2019, Variance risk in aggregate stock returns and time-varying return predictability, Journal of Financial Economics 132, 150-174.

Rapach, David E., Jack K. Strauss, and Guofu Zhou, 2010, Out-of-sample equity premium prediction: Combination forecasts and links to the real economy, Review of Financial Studies 23, 821-862.

Roll, Richard, 1977, A critique of the asset pricing theory's tests Part I: On past and potential testability of the theory, Journal of Financial Economics 4, 129-176.

Sadka, Ronnie, and Anna Scherbina, 2007, Analyst disagreement, mispricing, and liquidity, Journal of Finance 62, 2367-2403. 
Sharpe, William F., 1964, Capital asset prices: A theory of market equilibrium under conditions of risk, Journal of Finance 19, 425-442.

Tédongap, Roméo, 2015, Consumption Volatility and the Cross-Section of Stock Returns, Review of Finance 19, 367-405.

Van Nieuwerburgh, Stijn, and Laura Veldkamp, 2010, Information acquisition and underdiversification, Review of Economic Studies 77, 779-805.

Veldkamp, Laura L., 2005, Slow boom, sudden crash, Journal of Economic Theory 124, $230-257$.

Welch, Ivo, and Amit Goyal, 2008, A comprehensive look at the empirical performance of equity premium prediction, Review of Financial Studies 21, 1455-1508. 